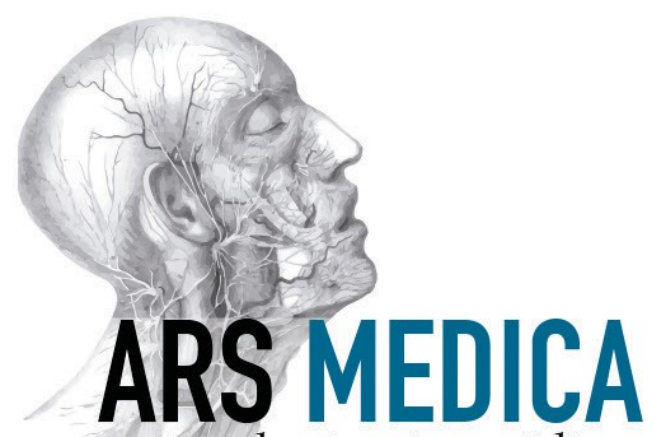

El presente artículo corresponde a un archivo originalmente publicado en Ars Medica, revista de estudios médicos humanísticos, actualmente incluido en el historial de Ars Medica Revista de ciencias médicas. El contenido del presente artículo, no necesariamente representa la actual línea editorial. Para mayor información visitar el siguiente vínculo: http://www.arsmedica.cl/index.php/MED/about/submissions\#authorGuidelines 


\title{
Estableciendo lazos entre Darwin y Jung: La selección natural, el inconsciente colectivo y el proceso de individuación.
}

\author{
Rafael Estay Toloza \\ Profesor Auxiliar \\ Departamento de Psiquiatría \\ Facultad de Medicina \\ Universidad de Valparaíso \\ Gustavo Figueroa Cave \\ Profesor Titular \\ Departamento de Psiquiatría \\ Facultad de Medicina \\ Universidad de Valparaíso
}

\section{Resumen}

Estamos celebrando doscientos años del nacimiento de Darwin y ciento cincuenta desde la publicación de El origen de las especies. El mérito de Darwin fue ser el primero en plantear que las especies no fueron creadas todas simultáneamente y para siempre, sino que evolucionan en el tiempo adaptándose a su medio ambiente. La evolución es tanto física como mental. Los individuos mejor adaptados al medio se van a reproducir en mayor número que los otros y tendrán una descendencia más numerosa que perpetúe sus genes. Ningún cambio que afecte a un progenitor va a quedar sin ser transmitido a su descendencia.

Carl G. Jung manifiesta que los seres humanos compartimos una semejanza psíquica, cuyabase está dada por el inconsciente colectivo, que a su vez está compuesto por los arquetipos. El inconsciente colectivo es igual en todos nosotros y se ha ido formando a lo largo de millones de años de evolución. Es el sustrato de la conciencia. La aparición de la conciencia tiene que haber tenido, y seguir teniendo, una importante ventaja evolutiva; en caso contrario, y siguiendoa Darwin, no se habría perpetuado. Jung expresa que el proceso de individuación, que es un arquetipo, implica ir haciéndose cada vez más consciente, incorporando al inconsciente en un trabajo constante que lleva a que el individuo más exitoso esté armonizado consigo mismo y su devenir. En términos religiosos, será aquel que, a través de la gracia divina, ha sometido la propia a la voluntad divina.

Nos preguntamos si la evolución psíquica no nos llevará a ir facilitando las condiciones para que dicha gracia divina se exprese en la conciencia del ser humano. 
palabras clave: Darwin; Jung; selección natural; proceso de individuación; inconsciente colectivo.

\section{ESTABLISHING TIES BETWEEN DARWIN AND JUNG: NATURAL SELECTION, THE COLLECTIVE UNCONSCIOUS AND THE PROCESS OF INDIVIDUATION}

We are celebrating two hundred years since the birth of Darwin and one hundred and fifty years since the publication of The Origin of Species. The merit of Darwin was being the first one to argue that the species were not created all at once and for always, but that they evolved over time, having adapted to their environment. Evolution is physical as mental as well. The individuals better adapted to the environment will reproduce in greater number than othersand will have more offspring to perpetuate their genes. All changes that affect a progenitor are transmitted to its descendants.

Carl G. Jung declares that we human beings share a psychic resemblance, the foundation of which is the collective unconsciousness, which at the same time is composed of archetypes. The collective unconsciousness is the same in all of us and has been taking shape over millions of years of evolution. It is the so-called substrate of consciousness. The consciousness must havehad, and still has, an important evolutionary advantage; otherwise, and according to Darwin, it would have not perpetuated.

Jung manifests that the individuation process, which is an archetype, implies becoming increasingly conscious, incorporating the unconsciousness in a constant process that allows the most successful individual are in harmony with their present and emerging self. In religious terms, they will be the ones that, through divine grace, have submitted their own will to the divinewill. We ask ourselves if psychical evolution will not bring us then to facilitate the expression of such divine grace in the consciousness of the human being.

Key words: Darwin; Jung; natural selection; individuation process; collective unconsciousness.

Estamos celebrando 200 años desde el nacimiento de Darwin y 150 años de lapublicación de El origen de las especies ${ }^{1}$. ¿Cuáles son las razones de tanta celebración? En la actualidad nos parece como casi evidente que las especies evolucionen,tanto como que la tierra gire en torno al sol y no al revés, o que sea redonda y no plana. Pero no olvidemos que no siempre fue así. Hace tan sólo siglo y medio la evolución de las especies era algo que no estaba dentro de lo 
imaginado, conocido ni aceptado; menos aún, la posibilidad de que el hombre pudiese "descender del mono". Se estaba convencido que las especies habían sido creadas todas de una vez y para siempre. No existía la evolución como concepto ni menos como realidaddelante de nuestra vista. Ahí reside el mérito principal de Darwin. Fue el primero que propuso que la selección natural trae implícita la evolución de las especies.

Para ser más precisos, hablando con propiedad, no fue el primero. Ya su abuelo Erasmus Darwin, en su libro Zoonomía, escribía de la lucha por la existencia, de la evolución y de la posibilidad de un tronco común como origen detodos los seres vivos.

Charles Darwin se había graduado de teología en el King’s College de Cambridge,lo que lo facultaba para ejercer como pastor de la iglesia anglicana, y por ello se daba perfecta cuenta de lo revolucionarias que iban a resultar sus ideas y propuestascientíficas. Esto lo hizo ir postergando su publicación por cerca de 20 años. En el intertanto, iba sufriendo de mala salud crónica, la que se extendería por el resto de su vida. Es bastante probable que muchas de sus múltiples dolencias digestivas, cefaleas y debilidad, hayan tenido un sustrato sicosomático. Resulta decidor que en un diario de salud que mantuvo por cerca de cuatro años, consignara todos los días su condición física, si se sentía enfermo, muy enfermo, o simplemente mal $^{2}$. Darwin le temía al rechazo y a ser ridiculizado. Además, no era un hecho menor enfrentarse a las firmes creencias religiosas de su esposa Emma. Durante toda su vida guardó una carta en que ella le señalaba el temor de que la ciencia lo llevara a un escepticismo cada vez mayor, que sus doctrinas los pudiesen separar e impedir reunirse en la otra vida. En un margen Darwin anotó esta decisiva sentencia: "cuando haya muerto, recuerda que muchas veces he besado esta carta y llorado sobre ella"3.

En el año 1844 ya tenía listo un ensayo con las ideas que publicaría 15 años después. Incluso en una carta a ser abierta sólo en caso de que falleciera, le pide a Emma que lo publique póstumamente como su legado. Le expresa que estáconvencido que su teoría es cierta y que constituirá "un paso considerable para la ciencia”. Sin embargo dicho ensayo nunca se publicó. Puede que haya tenido una influencia decidora la aparición anónima de Vestiges of the Natural History of Creation en ese mismo año. El libro, que en esencia estaba en línea con las ideas de Darwin, adolecía de peso científico y generó un encendido debate y serias descalificaciones en los círculos intelectuales. El autor, Robert Chambers, periodista escocés, estaba tan consciente del torbellino que produciría su escrito, que prefirió permanecer en el anonimato. 
Por su parte, Darwin presentaba y comentaba sus hallazgos con otros investigadores, miembros de diferentes sociedades científicas. Fueron dichos colegas (especialmente Charles Lyell, geólogo, y Joseph Hooker, botánico) quienes lo impulsaron a publicar su libro. El empujón final provino del escrito que recibió de un joven naturalista que trabajaba en Malasia, Alfred R. Wallace, titulado De las tendencias de las variedades a separarse indefinidamente del tipo original, en que planteaba los mismos hechos desarrollados por Darwin. Fue así como el trabajo de Wallace y el de Darwin fueron presentados conjuntamente en la Linnean Society deLondres el $1^{\circ}$ de julio de 1858, en una reunión extraordinaria en la que los amigos de Darwin consiguieron, a última hora, incluir ambas contribuciones. Darwin no pudo asistir pues 3 días antes había fallecido de escarlatina su hijo Charles.

El 24 de noviembre de 1859 vio la luz la primera edición de El origen de las especies, con una tirada de 1.250 ejemplares que se agotaron el primer día, siendo impresa una segunda de 3.000 ejemplares, a su vez vendida en menos de una semana.Lo que se dice un best seller, y eso que no era barato, costaba 14 chelines, que era el salario de más de una semana de un trabajador promedio ${ }^{4}$. Lo revolucionario radicó en que planteaba por primera vez, y de manera explícita, el concepto de selección natural, definido por Darwin como "la perpetuación de las variaciones útiles y la eliminación de las nocivas, por más mínimas que sean"5. Es decir, las especies se van adaptando al medio en que viven, desarrollando cambios, modificaciones, variaciones; esto es, van a hacer que aumente el número de miembros de la misma. Los individuos mejor adaptados al medio son los que se reproducen en mayor cantidad con el correr del tiempo.

Darwin pensaba que la evolución no tiene una meta final: "me parece que no existe más designio preconcebido en la variación de los seres orgánicos y en la acción de la selección natural que en la dirección del viento"6. No obstante, tambiénmanifiesta, quizás de manera contradictoria, que "cada ser, y ésta es la meta final delprogreso, tiende a perfeccionarse cada vez más en relación a sus condiciones"7.

Hace unos cinco millones de años nuestros “primos”, los grandes simios(especialmente el chimpancé) y las ramas que llevan al surgimiento de nuestra especie, se separaron definitivamente. La aparición del Australopitecus con su marcha bípeda constituye un hito. Sin embargo, llama la atención que hubo de pasar más de un millón de años antes de que se fabricaran las primeras herramientas, gracias a una nueva especie, el homo erectus. En éste la capacidad craneana se expande dramáticamente desde alrededor de 450 centímetros cúbicos de los Australopitecusa más del doble. De hecho, el homo erectus es 
prácticamente igual a nosotros desde el cuello hacia abajo, muy probablemente de una estatura mayor, siendo la primera especie en migrar fuera de África ${ }^{8}$. Con el erectus asistimos al nacimiento de un atributo que podríamos caracterizar como propiamente humano, el lenguaje. Para que aparezca el lenguaje también tiene que hacerlo la conciencia. Ambos van tan estrechamente ligados, que no se sabe dónde comienza uno y termina la otra. Ahorabien, el crecimiento del cerebro continúa y finalmente (al menos hasta la actualidad) tenemos al homo sapiens sapiens con alrededor de 1300 cc. (curiosamente el homo sapiens neanderthalis tenía mayor capacidad craneana que nosotros y está extinto). Entonces, en alrededor de 1,5 millones de años resulta que prácticamente se triplica el tamaño del cerebro ${ }^{9}$.

La selección natural actúa con extrema lentitud. Las escalas del tiempo humano,de la especie homo sapiens sapiens, aparecida alrededor de 150.000-200.000 años atrás, no son suficientes para explicar los enormes cambios ocurridos desde entoncesen la capacidad mental. Justamente eso es lo que más llama la atención y necesita una explicación especialmente sutil.

La naturaleza no suele hacer experimentos tan dramáticos, menos aún cuandoesos experimentos conllevan un consumo elevado de energía y, según sabemos, el cerebro es un gran demandante de energía. Si ese aumento de tamaño no implicara una clara ventaja evolutiva no se habría mantenido, la selección natural se hubiera encargado de eliminarlo sin más. Además, surge una segunda interrogante. ¿Por quéhubo de aparecer una capacidad mental con tantos años de adelanto? ¿Que necesidadexistía de que una mente de la edad de las cavernas tuviera la posibilidad de hacer filosofía o cálculo integral, o de viajar al espacio? Es conocido que compartimos más del $97 \%$ de los genes con los chimpancés, nuestros más cercanos parientes, y, no obstante, ellos siguen viviendo en un hábitat bastante reducido y su población total es millones de veces menor que la del homo sapiens, que no tiene barreras en los ecosistemas en que es capaz de morar. De hecho, es el único ser viviente que habita en todo nuestro planeta y, en un futuro muy cercano, seguramente lo hará fuera de él por largos períodos. Si consideramos el número total de individuos de nuestra especie y la gran cantidad de medios ambientes diferentes que habitamos, no cabe duda de que la especie humana ha sido exitosa.

¿Es así, entonces, que la conciencia representa una ventaja evolutiva? Laconciencia nos permite explorar situaciones nuevas, nos saca de la rigidez de los instintos, nos facilita la adaptación y el acomodo a variables en continuo cambio o, incluso, absolutamente nuevas (por ejemplo, la vida en el espacio, o la misma existencia en megápolis que suman más población que la que había en toda la Tierra cuando 
surgimos como especie). La conciencia posibilita el surgir de una noción de nosotros mismos, o sea, un self. Es a través del self que podemos ponernos en el lugar del otro, leer sus afectos, anticipar sus sentimientos, entender sus reacciones, lo que es imprescindible en los grupos cada vez más numerosos y complejos en los que vivimos. ¿Es posible la empatía y compasión sin un self que se reconozca y se reconozca en los demás?

Darwin hizo notables observaciones psicológicas, adelantándose en décadas a Freud. Plantea que un animal puede verse impulsado a desarrollar actividades tanto por el sufrimiento, dolor, hambre, sed o miedo; como también por el placer de comer, de beber, de propagar la especie. Agreguemos nosotros que, siguiendo alarquetipo de la individuación planteado por Carl G. Jung, también por el placer queproduce el conocimiento en sí. Si los primeros se mantienen de manera prolongadavan a causar depresión disminuyendo la capacidad de adaptación. Contrariamente, las situaciones que producen placer pueden continuar durante mucho tiempoestimulando todo el sistema y aumentando su actividad. Señala: “Así, pues, ha ocurrido que la mayoría o totalidad de los seres sensibles han sido desarrollados de tal manera por la selección natural, que las sensaciones que les procuran placer les sirven de guía habitual..., la suma de estos placeres...da, no puedo dudar de ello,un excedente de felicidad sobre los dolores" ${ }^{10}$.

Darwin afirma que probablemente ningún cambio que afecte a un progenitor, sea cual sea dicho cambio, pase sin dejar rastro sobre su descendencia. Agrega que "podemos tener la certeza que existe un gran número de caracteres perdidos dispuestos a manifestarse en las condiciones convenientes. ¿Cómo poder hacer inteligible y vincularla a otros hechos esta propiedad general de retorno, este poderde recordar y de hacer revivir caracteres perdidos desde hace largo tiempo?"11.

En la idea anterior está enunciado, aunque de manera implícita, el concepto de inconsciente colectivo y sus constituyentes, los arquetipos, piedras angulares enla Psicología Analítica de Carl Jung, llamando la atención la íntima concordancia entre el planteamiento darwiniano y la perspectiva jungiana.

¿En qué vemos esta concordancia? Darwin plantea que cualquier adaptación que hayan experimentado los padres a su medio, aunque dicha variación hayaacontecido mucho tiempo atrás, va a ser transmitida a su descendencia. Si las circunstancias así lo ameritan, se va a producir la expresión de una manifestación que hasta ese momento estaba latente, y a través de la selección natural se van a ir seleccionando, de las múltiples copias posibles, aquellas que en su conjunto representen la mejor adaptación a su ambiente. Por su parte 
Jung hablando del acontecerpsíquico, asevera que las características que definen a lo humano son transmitidas mediante los arquetipos, que son múltiples y tienen un sustrato biológico. Van a permanecer dormidos -de hecho, algunos, o la gran mayoría de ellos, nunca se van a expresar- hasta que sea necesario. Pero hay unos pocos que cristalizan con inusitada frecuencia (como los arquetipos de la sombra, del ánima/animus, y del self).Siguiendo lo expresado por Darwin, es la selección natural, en este caso actuando sobre las características mentales de nuestra especie, la que ha ido posibilitando la formación de un paradigma mental humano, que es transmitido en los arquetipos que, a su vez, son los constituyentes del inconsciente colectivo.

Jung plantea que el inconsciente consta de dos partes, el inconsciente personal yel inconsciente colectivo ${ }^{12}$. Este último lo compartimos y es el mismo en todos nosotros, homo sapiens sapiens. Lo que sucede es que las diferentes culturas lo moldeany hacen que su manifestación no sea igual. Es decir, la expresión del inconsciente colectivo es mediada por la cultura; más aún, para que se plasme el inconsciente colectivo es fundamental que exista una cultura determinada. Entendemos a lacultura como el conjunto de acciones, creencias, conductas, mitos, etc., que no es heredado genéticamente sino que es transmitido por la interacción social.

El inconsciente colectivo se fue desarrollando a lo largo de millones de añosde evolución. Así como surgió una forma corporal, también lo hizo un atributopsíquico específicamente humano. El inconsciente colectivo está formado porlos arquetipos* que son posibilidades de funcionamiento psíquico, posibilidadesde aprendizaje y posibilidades de desarrollo ${ }^{13}$. Es un esquema a ser llenado de contenido en el momento necesario. No se trata de una fotografía ni de algo predeterminado, fijo e inmodificable. Mientras los instintos sí lo son, no sucede lomismo con los arquetipos, que son moldeados por la cultura. Hay una suerte decontinuo interjuego. Los arquetipos que dan forma a lo "humano" sólo pueden expresarse si hay una cultura "humana” que les posibilite dicha expresión; asu vez, la cultura se va a instaurar y a sufrir cambios únicamente si primero se plasman los arquetipos. Jung dice que el arquetipo "es un orden de funcionamiento mental, de la misma manera que, por ejemplo, nuestro funcionamientobiofisiológico sigue un esquema" ${ }^{14}$.

Jung da un paso más que ilumina psicológicamente lo afirmado por Darwinen el plano biológico. De acuerdo a Jung, a medida que va transcurriendo la vida van presentándose diferentes tareas que deben ser resueltas. El ser humano nace con un yo rudimentario a partir de una psique en que prácticamente todo es inconsciente. Es necesario que se establezca un yo -entendido como el centro dela personalidad 
consciente-, es decir, se precisa que éste vaya floreciendo desde el inconsciente y, con el transcurrir del tiempo, se reconozca como autónomo e independiente. A continuación va a aparecer el self, que contiene al yo. El self es una instancia más completa que el yo pues incorpora lo consciente y lo inconsciente a través de la expresión del arquetipo de la función trascendente ${ }^{15,16}$,que justamente va a propender y a posibilitar la comunicación entre ambos. Sellama función trascendente a aquella mediadora o traductora de los diferenteslenguajes hablados por dichas instancias. Sin embargo, es requisito previo que se haya establecido un observador, el yo, desde donde se pueda ir construyendo el self ${ }^{17}$.

Todo apunta a que la primera parte de este desarrollo, la aparición del yodesde el inconsciente, está acotada por un fuerte componente genético. Si el yono se constituye de cierta manera, si no reconocemos en él una cierta humanidadbásica, estaremos hablando de una severa patología, por ejemplo una esquizofrenia o un autismo. En esa manera de hacerse yo, es la selección natural la que facilitó y encauzó la manifestación de un arquetipo humano. Luego, a lo largo dela lucha por la vida, se va produciendo lo que Jung llama acertadamente proceso de individuación ${ }^{18,19}$. Éste consiste en un constante descubrimiento y ensanchamiento de los límites del self, en que cada vez el individuo se va haciendo máspropio, más él mismo, más armónico con su devenir y más en consonancia conel de los demás. De hecho, Jung dice que el proceso de individuación exitoso esaquel que nos conduce a que en la última etapa de la vida estemos preparados para bien morir.

Hacia finales de su vida Jung deja de lado la cautela anterior, se declara creyentey proclama, sin ambages, que somos "en el sentido más profundo, las víctimas o los medios e instrumentos del amor cosmogónico" ${ }^{20}$. No es posible vivir la vida en plenitud sin un sentido y ese sentido se lo da la manifestación de lo divino en el hombre. Para Jung Dios es amor, Dios es sentido. Ambos significados se unen en la traducción de la palabra china tao, que puede ser entendida como Dios y como sentido ${ }^{21}$. A medida que fue aflorando nuestra conciencia a lo largo de miles de años de evolución, que simbólicamente podemos entender como haber comidode la fruta prohibida -haber salido de la inconsciencia del jardín del edén y haber probado del árbol del conocimiento-, fue surgiendo también un nuevo arquetipo, el impulso religioso $^{22}$.

Jung dice que no hay manera de probar la existencia o no existencia deDios, pero que representa una indesmentible ventaja comparativa ser creyente y que la vida tenga un sentido trascendente, especialmente en 
su segunda mitad.Señala que "la muerte será armónica cuando la vida misma haya sido armónica y rica en sentido”23.

Hacer las paces con Dios es equivalente a aceptarse y reconciliarse consigo mismo. Sólo en esas circunstancias se ha logrado una armonía con el devenir, pues,de alguna manera, se ha sacrificado la voluntad propia sometiéndola y ofreciéndoselaa la divina. En términos psicológicos, significa que se ha considerado e incorporadoen su justa magnitud a lo inconsciente. El self es, como expresa Jung, el lugar donde se manifiesta lo divino. "El sí mismo es la imagen de Dios en el hombre”"24, y va aun más allá, señalando que al sí mismo "podría designársele igualmente como el Dios en nosotros”25. Aunque precisa con pulcritud que no quiere decir que “yo crea que Dios es el sí mismo o el sí mismo es Dios”26.

Volvamos al impulso religioso. Jung afirma que los símbolos religiosos no representan la sublimación de alguna cosa distinta -por ejemplo la sexualidad,como postulaba Freud-, sino que tienen una existencia por sí mismos. En la psiqueexiste una función religiosa primaria. Por función religiosa entiende la observacióncuidadosa y concienzuda de lo numinoso. Lo numinoso es aquello que causa respeto y temor reverencial y que provoca una especial modificación de la conciencia.La religión es "una actitud especial del espíritu humano, actitud que... podemos calificar de consideración y observación solícitas de ciertos factores dinámicos(espíritus, demonios, dioses, ideas, ideales) que...la experiencia le ha presentado como lo suficientemente poderosos, peligrosos o útiles para tomarlos en respetuosaconsideración; o lo suficientemente grandes, bellos y razonables para adorarlos piadosamente y amarlos"27.

Está claro que Jung creía en una teleología de la vida a diferencia de Darwin, aunque, como vimos más arriba, por momentos éste fue ambiguo. La teleología se expresa a través del arquetipo del proceso de individuación, en que cada vez se va incorporando más material consciente desde el inconsciente, en una dialéctica de nunca acabar. Quizás podríamos decir que las experiencias cumbre, los éxtasis, los samadhi, la conciencia cósmica, etc., representan el conocimiento total, la armoníay entendimiento final. En el ámbito psicológico, es la unión del consciente con el inconsciente. En términos religiosos es la realización de la divinidad en nosotros. Es recibir la gracia divina en plenitud. Al respecto, nos preguntamos si justamente una de las manifestaciones del avance evolutivo sería que se puedan ir construyendo progresivamente, más adecuadamente y con mayor facilidad, las condiciones necesarias para que se manifieste la plenitud del conocimiento. Si lo consignamos desde la perspectiva religiosa, 
diríamos, facilitar la expresión de la gracia divina, que es ese delta que nos falta para comulgar con Dios.

Sus estudios antropológicos le permitieron a Jung postular un giro de la humanidad con respecto a Dios. En las sociedades primitivas el contacto con Dios estaba monopolizado por el rey, los brujos o los chamanes; el gran cambio cultural del cristianismo es que Dios se masificó, pudiendo manifestarse en cada uno de nosotros ${ }^{28}$.

Darwin decía que la meta final de todo ser viviente es perfeccionarse cada vezmás de acuerdo a sus condiciones. Por su parte, Jung manifiesta que la condición previa a toda acción que aspire a ser responsable es el conocimiento de uno mismo y la armonía con la propia manera de ser. Si el hombre/mujer, sobre todo en la segunda mitad de su existencia, sigue vistiéndose con ropajes ajenos, siguiendo derroteros que no están en consonancia con su devenir más propio, va a enfermarsey desarrollar una neurosis. Es decir, es fundamental atenerse y ser fiel al proceso de individuación.

Es así como las culturas más evolucionadas van a ser aquellas que le permitana cada individuo desarrollar y desplegar al máximo sus potencialidades inherentes.Sólo de esta manera la cultura se transforma en un verdadero acelerador evolutivo y se sale de los condicionantes biológicos que siguen un ritmo mucho más pausado ${ }^{29}$. Pero no olvidemos que toda cultura también padece de una enorme inercia y los cambios son resistidos por ella misma. Mientras menos evolucionada sea, más restrictiva se va a comportar, frenando toda posibilidad de crecimiento y perfeccionamiento individual de sus miembros; la menor desviación de lo conocido será experimentado como una amenaza y se propenderá hacia una uniformidad forzada que, por lo mismo, va a asfixiar la libre expresión, la creatividad y desarrollo de susmiembros. Las sociedades más primitivas son más prejuiciosas, pues el prejuicio es un economizador de energía psíquica debido a que facilita las decisiones. Pero para ello tiene que recurrir a una simplificación extrema de la realidad e inculcárselapor igual a todos sus integrantes. Como regla general, las sociedades no fomentan la individuación sino la conformidad.

No obstante, de vez en cuando aparecen ciertas personas que abren nuevos caminos que posibilitan y fomentan el desarrollo y la evolución a un ritmo mucho mayor de lo que sería esperable basado sólo en la selección natural biológica. Es decir, entra en escena una selección natural cultural. Aquella sociedad que impulse, promueva y entregue las mejores condiciones para que ello ocurra, va a ser la que avance a mayor velocidad en el camino evolutivo ${ }^{30}$. Justamente el mayor mérito de Darwin fue ser uno de aquellos individuos que transforman de raíz 
el paradigma cultural, pues a pesar de todas las reticencias culturales propias de la era victoriana, fue capaz de atar cabos sueltos, de mirar de frente la realidad, sopesar las evidencias y enunciar una teoría absolutamente novedosa, revolucionaria -tanto, que tuvieron que pasar casi 90 años para que fuera aceptada por la iglesia anglicana, en la que Darwin estaba facultado como pastor. Es decir, se pudo alzar por encima de sus propios condicionantes culturales, pues, usando la terminología jungiana, era la única manera de darle curso a su proceso de individuación sacandode sí el flujo creador. A su vez, Jung pudo vislumbrar los aciertos de Darwin y, sin decirlo de manera explícita, hacer uso de ellos audazmente de acuerdo a su propia e intransferible individualidad, insertado como estaba él en una sociedad y en un siglo diferentes.

\section{Citas}

${ }^{1}$ Darwin C. (1983). El origen de las especies, Madrid, Sarpe.

${ }^{2}$ Browne J. (2007). La historia de El origen de las especies, de Charles Darwin, Buenos Aires, Debate, pág. 57.

${ }^{3}$ Ibíd, pág. 50.

${ }^{4}$ Ibíd, pág. 18.

${ }^{5}$ Darwin C. (1972). Teoría de la Evolución, Barcelona, Ediciones Península, pág. 39-40.

${ }^{6}$ Ibíd, pág. 239.

${ }^{7}$ Ibíd, pág. 81.

${ }^{8}$ Leaky R. (1992). Origins reconsidered, New York, Doubleday.

${ }^{9}$ Ornstein R. (1991). The Evolution of consciousness, New York, Simon and Schuster Paperbacks.

${ }^{10}$ Cf. Darwin C., óp. cit., pág. 240.

${ }^{11}$ Ibíd, pág. 218-219.

${ }^{12}$ Jung C. (2002). Los arquetipos y lo inconsciente colectivo, Obra Completa, Volumen 9/1, Madrid, Editorial Trotta.

* El arquetipo es colectivo, pero su manifestación es individual. Es 
biológico, se trae de nacimiento, se aloja en el cerebro y de alguna manera organiza y ordena su funcionamiento. Es como una fuerza dinámica presta a entrar en acción si es necesario. Lo podemos visualizar como el lecho de un río que, en condiciones ideales, va a conducir el fluir del caudal de la vida y sus múltiples aconteceres, de manera controlada evitando inundaciones. Existen múltiples cauces de ríos -arquetipos- pero sólo se va a hacer consciente aquel al que le llegue caudal y se represente. A su vez, las compuertas que lo regulan están controladas por nuestras funciones mentales. Es así que el lecho del río es colectivo, pero el tipo de flujo, la magnitud del caudal y el manejo del mismo, son individuales.

${ }^{13}$ Estay R. (2008). Jung en fácil. Santiago, Pehuén.

${ }^{14}$ Evans R. (1968). Conversaciones con Jung. Madrid, Ediciones Guadarrama, pág. 79.

${ }^{15}$ Cf. Jung C. Los arquetipos y lo inconsciente colectivo. Obra Completa, Volumen 9/1,párr.524.

${ }^{16}$ Jung C. (1985). Tipos Psicológicos. Buenos Aires, Editorial Sudamericana, pág. 281-291.

${ }^{17}$ Cf. Estay R., óp. cit., pág. 99-105.

${ }^{18}$ Jung C. Conciencia, Inconsciente e Individuación, en Los arquetipos y lo inconsciente colectivo, Obra Completa, Volumen 9/1, pág. 257271.

${ }^{19}$ Von Franz M.L. El proceso de individuación. En C. Jung, El hombre y sus símbolos, Barcelona, Caralt, 1997, pág. 157-228.

20 Jung C. (1981). Recuerdos, sueños, pensamientos. Barcelona, Seix Barral, pág. 357-358.

${ }^{21}$ Jung C., Wilhelm R. (1982) El secreto de la flor de oro. Barcelona, Paidós.

${ }^{22}$ Jung C. (1981). Psicología y religión. Barcelona, Paidós.

${ }^{23}$ Jung C. (2004). La dinámica de lo inconsciente. Obra completa, Volumen 8, Madrid, Editorial Trotta, párr.809.

${ }^{24}$ Cf. Jung C. Recuerdos, sueños, pensamientos, pág. 214. 
${ }^{25}$ Jung C. (1990). Las relaciones entre el yo y el inconsciente. Barcelona, EditorialPaidós, pág. 141.

${ }^{26}$ Cf. Evans R. Conversaciones con Jung, pág. 91.

${ }^{27}$ Jung C. Psicología y religión, pág. 23.

${ }^{28}$ Jung C. (2006). La práctica de la psicoterapia. Obra completa, Volumen 16, Madrid, Editorial Trotta, pág. 106.

${ }^{29}$ Lawson T. (2008). Carl Jung, Darwin of the mind. London, Karnac.

${ }^{30}$ Fischer A. (2004). Nuevos paradigmas a comienzos del tercer milenio. Santiago, El Mercurio Aguilar. 